\title{
2D Frost Growth and Densification Model in Counterflow Heat Exchanger
}

\author{
Alexandre Coulombe*, Hachimi Fellouah, Sébastien Poncet \\ Mechanical engineering department, Université de Sherbrooke \\ 2500 boulevard de l'université, Sherbrooke (QC), J1K 2R1 Canada \\ *Corresponding author: Alexandre.Coulombe@usherbrooke.ca
}

\begin{abstract}
When a heat recovery ventilator is operating under winter conditions, the water vapor present in the exhaust airflow can lead to frost formation. The outside temperature at which frost formation occurs depends on many variables such as the heat exchanger plate temperature, the exhaust air humidity ratio, the exhaust airflow and the plate spacing. In this study, a new 2D frost formation model is proposed and applied to counterflow parallel plate heat exchangers. The method is based on a frost growth and densification model. The frost densification depends on the square root of the time and the ratio of supercooling and supersaturation degree. An energy balance equation for the heat conduction through the frost layer and the heat and mass transfer from the moist air to the frost layer is used as a convergence criterion on the frost surface temperature prediction. The proposed 2D model showed that the airflow from a $2.5 \mathrm{~mm}$ parallel plate spacing heat exchanger can be reduced as much as $33 \%$ over a 25 minutes period. While a larger plate spacing, such as a $4.0 \mathrm{~mm}$ spacing, is less prone to airflow reduction due to frost growth, less than $5 \%$ reduction over the same time period, the $2.5 \mathrm{~mm}$ spacing is still more efficient than the $4.0 \mathrm{~mm}$ spacing at the end of the 25 minutes period, with efficiencies of $77 \%$ and $55 \%$ respectively.
\end{abstract}

Keywords: Numerical Modelling, Frost Formation, Parallel Plate Heat Exchanger

\section{Introduction}

In the last 60 years, building code requirements have increased building envelope airtightness. The improved airtightness, combined with better insulation, reduces the annual space heating energy per square meter of the houses by 45\%. However, this improved airtightness created an air quality issue [1]. Modern houses being so airtight, natural air infiltration became insufficient to maintain an acceptable air quality for its occupants. To compensate for the lower air infiltration rate, building regulations were adopted and either specified the minimum air change per hour rate or fresh airflow per occupant or bedroom to be provided by a balanced ventilation system (the air exchanger) [2], [3], [4]. These building codes and regulations also specified a minimum sensible heat recovery efficiency. Efficiency requirements being as high as $75 \%$, heat recovery ventilators used in Nordic climates are more prone to frost build-up inside the heat exchanger [5].

When humid exhaust air is cooled in the air exchanger while operating in sub-freezing temperature, water vapor is cooled to the point where three different regions are present on the heat exchanger plates: the dry region, the condensation region and the frosted region [6]. Frost build-up can cause blockage of the airflow channels, increase the pressure drop across the exchanger and reduce the exhaust airflow. It has thus a negative impact on the indoor air quality [7, 8]. Frosting of the air exchanger core also affects the heat recovery efficiency negatively due to the increased heat conduction resistance [9]. To maintain the air quality and heat recovery efficiency, defrosting cycles are used periodically [10].

Frost formation can be divided in three periods known as the crystal growth period, the frost layer growth and frost layer full growth. Since most of the frost growth occurs during the frost layer growth period, models were developed to link the frost density, among other parameters such as the cold surface temperature, frost porosity and Reynolds number to its thermal conductivity during this phase. Most of the thermal conductivity models are either empirical or semi-empirical [11].

To the best of the authors knowledge, it is the first time that a 2D frost growth and densification model is applied to an air-air counterflow heat exchanger to predict heat recovery efficiency degradation over time when operating under 
freezing conditions. To achieve this, mass and heat balances are invoked using empirical correlations for the frost densification and Nusselt number.

\section{Proposed 2D model}

The proposed 2D model in this study predicts the performance degradation over time of a counterflow parallel plate heat exchanger when used under frosting conditions. In these conditions, frost only occurs on the exhaust side of the heat exchanger where stale humid air from the house is cooled down. On the supply side, no frost occurs, and humidity ratio is negligible. The following hypotheses were applied: the two counter airflows are fully developed and laminar before entering the heat exchanger; the heat exchanger plate thermal resistance and frost thermal conduction in the airflow direction are negligible.

\subsection{Frost growth and densification model}

Previous work from Hermes [12] proposed a relation for the heat flux continuity at the frost surface considering a prescribed surface temperature and invoking an energy balance equation at the frost air interface:

$$
k_{f} \frac{T_{s}-T_{w}}{\delta}=h\left(T_{a}-T_{s}\right)+\frac{h}{C_{p}}\left(\omega_{a}-\omega_{s}\right) i_{s v}
$$

where $\mathrm{kf}$ is the frost thermal conductivity, Ts the frost surface temperature, Tw the wall temperature, $\delta$ the frost thickness, $\mathrm{h}$ the heat transfer coefficient, Ta the air temperature, $\mathrm{Cp}$ the air specific heat, $\omega$ a the air humidity ratio, $\omega \mathrm{s}$ the saturated air humidity ratio and isv the latent heat of sublimation.

They considered a semi-empirical correlation to describe the evolution of the frost porosity $\varepsilon$ as a function of time $\mathrm{t}$ and a modified Jakob number $\Lambda$. As the frost porosity decreases, its density increases. When the porosity equals zero, the frost density equals solid ice density. The constants were fitted from experimental data for an airflow between parallel cold plates [13]:

$$
\varepsilon=1-0.0022 \Lambda^{-3 / 4} \sqrt{t}
$$

where the modified Jakob number $\Lambda$ is the ratio between the sensible and the latent heat transfers. A lower modified Jakob number means that the frost densification will be faster.

\subsection{Operating conditions}

The heat exchanger parameters and inlet conditions are described in Tab.1. The domain length $\mathrm{L}$ was split in 30 cells. The airflow and frost properties were assumed to be constant on the width dimensions $\mathrm{W}$. Two spacings $\mathrm{H}$ were studied to compare the performance degradation of a tight spacing and a more opened one. The initial exhaust airflow and the supply airflow average velocity are denoted ua.

Table 1: Heat exchanger specifications and operating conditions.

\begin{tabular}{|l|l|l|l|l|l|}
\hline$\omega_{a}(\mathrm{~g} / \mathrm{kg})$ & $T_{c}\left({ }^{\circ} \mathrm{C}\right)$ & $H(\mathrm{~mm})$ & $L(\mathrm{~m})$ & $W(\mathrm{~m})$ & $u_{a}(\mathrm{~m} / \mathrm{s})$ \\
\hline 6.8 & -25.0 & $2.5,4.0$ & 0.3 & 0.3 & 0.65 \\
\hline
\end{tabular}

\subsection{Initial conditions}

To initialize the solution, the heat exchanger efficiency is assumed to be $75 \%$ for both plate spacings. With the heat exchanger inlet temperatures and efficiency known, the outlet temperatures are easily obtained from the enthalpy change of the exhaust airflow between the exchanger inlet and outlet. The temperature profile of both air flows is 
assumed to be linear between the inlet and outlet. The wall temperature is then set to be the average temperature of the air flows on each side.

\subsection{Airflow reduction from exchanger blockage}

This numerical model uses a typical air exchanger fan curve to decrease the exhaust airflow at each time step as the core pressure drop increases with the frost thickness. The supply airflow is considered constant over time and is equal to the initial exhaust air flow.

\subsection{Exhaust airflow properties}

The exhaust airflow temperature at the next downstream cell is computed from Eq.3 at every time step where Ta,exh is the exhaust air temperature at the position $\mathrm{x}$ and time $\mathrm{t}, \mathrm{q}$ the sensible heat flux and ma,exh the exhaust mass flow rate:

$$
T_{a, e x h}(x+1, t)=T_{a, \operatorname{exh}}(x, t)-\frac{2 q(x, t)}{\dot{m}_{a, e x h}(x, t)\left(C_{p}+h \cdot \omega_{a}(x, t)\right)}
$$

The exhaust air humidity ratio is computed for each cell at each time step from the water vapor mass conservation Eq.4 where the frost mass Mf is known from Eqs 1 and 2, assuming a constant ice density.

$$
\omega(x+1, t)=\omega(x, t)-\frac{M_{f}(x, t)-M_{f}(x, t-1)}{\dot{m}_{a, e x h}(x, t) d t}
$$

\section{Results}

For both plate spacings, a 25 minutes period was simulated to evaluate the growth of the frost. At the end of the 25 minutes, the frost thickness profiles are similar as seen in Fig.1a. However, the $2.5 \mathrm{~mm}$ spacing frost profile is shifted toward the exhaust exit compared to the $4.0 \mathrm{~mm}$ frost profile. Since the efficiency is higher in the tighter spacing, as seen in Fig.1b, the supply airflow is warmer when leaving the $2.5 \mathrm{~mm}$ heat exchanger at $\mathrm{x}=0 \mathrm{~mm}$ than the $4.0 \mathrm{~mm}$ spacing. The plate of the heat exchanger is thus warmer in this region, so no frost occurs before $x=90 \mathrm{~mm}$. Since the frost profiles are quite similar, the airflow reduction is more significant in the $2.5 \mathrm{~mm}$ configuration. The $2.5 \mathrm{~mm}$ exhaust airflow decreases by over $33 \%$ while the $4.0 \mathrm{~mm}$ one decreases by less than $5 \%$.

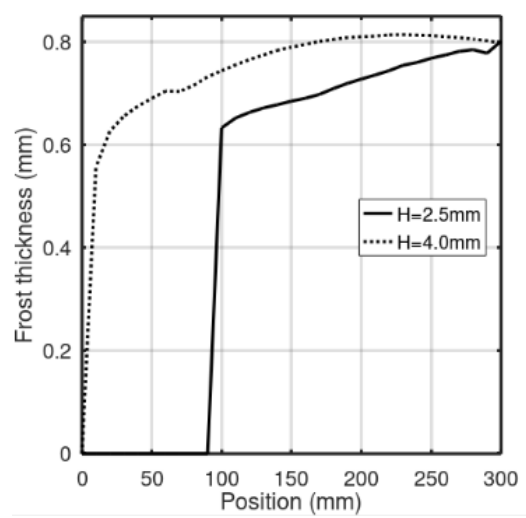

Fig. 1a: Frost thickness profile after 25 minutes.

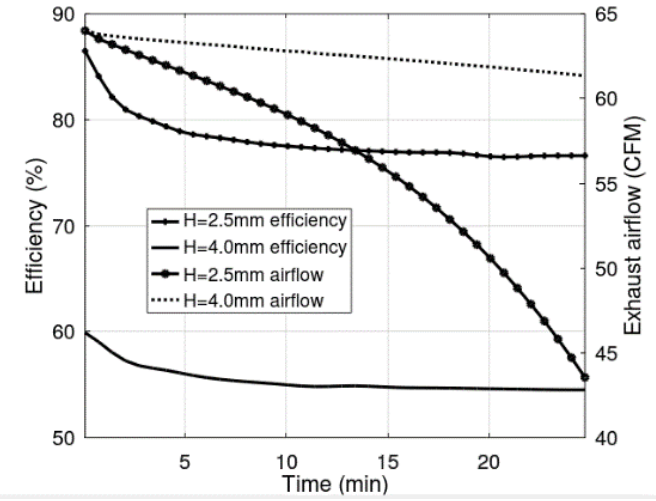

Fig. 1b: Heat exchanger performance degradation over time. 


\section{Conclusion}

In this paper, a new model was developed to predict frost growth and densification on a $2 \mathrm{D}$ geometry of a counterflow plate heat exchanger. This numerical model can predict the heat exchanger performance degradation under frosting conditions, the frost thickness and its associated exhaust airflow reduction. The plate spacing is an important parameter regarding the heat exchanger design as it increases the efficiency. However, tighter spacing are more prone to blockage and airflow reduction than larger spacings. This model could be improved by incorporating a condensation model to simulate the operating conditions where three different zones exist: the dry zone, the wet zone and the frosted zone. This range of operating conditions is more common than $-25^{\circ} \mathrm{C}$ winter conditions. This model could be used to optimize heat exchanger geometry and the defrost cycle interval to maximize heat recovery and indoor air quality.

\section{Acknowledgements}

The authors would like to acknowledge the financial support of Mitacs through the Acceleration grant of A.C. (IT13090).

\section{References}

[1] A. Parekh, L. Roux, and P. Gallant. Thermal and Air Leakage Characteristics of Canadian Housing. In11th Canadian Conference on Building Science Technology, Banff (Alberta), July 2007.

[2] ASHRAE. Standard 62.1-2019 Ventilation for Acceptable Indoor Air Quality. 2019.

[3] J.C Haysom and J.T. Reardon. Why Houses Need Mechanical Ventilation Systems, Institute for Research in Construction, 1998.

[4] National Research Council Canada. National Building Code of Canada 2015.

[5] Ministry of Municipal Affairs and Housing. Energy efficiency for housing. Supplementary standard SB-12, Institute of Research in Construction, 2016.

[6] M.R. Nasr, M. Fanchoux, R.W. Besant, and C.J. Simonson. A review of frosting in air-to-air energy exchangers. Renewable and Sustainable Energy Reviews, 30:538-554, 2014.

[7] W. Fisk, K. Archer, R. Chant, D. Hekmat, F. Offermann, and B. Pedersen. Performance of residential air-to-air heat exchangers during operation with freezing and periodic defrosts. In AHSRAE Transactions, volume 91, 1984.

[8] C. Beattie, P. Fazio, R. Zmeureanu, and J. Rao. Experimental study of air-to-air exchangers for use in arctic housing. Applied Thermal Engineering, 129:1281-1291, 2017.

[9] S. Anisimov, A. Jedlikowski, and D. Pandelidis. Frost formation in the crossflow plate exchanger for energy recovery. International Journal of Heat and Mass Transfer, 90:201-217, 2015.

[10] J. Zhang and A.S. Fung. Experimental and numerical investigation of the thermal impact of defrost cycle of residential heat and energy recovery ventilators. Energy and Buildings, 97:129-136, 2015.

[11] V.S. Nascimento Jr, F.R. Loyola, and C.J.L. Hermes. A study of frost build-up on parallel plate channels. Experimental Thermal and Fluid Science, 60:328-336, 2015.

[12] C.J.L. Hermes. An analytical solution to the problem of frost growth and densification on flat surfaces. International Journal of Heat and Mass Transfer, 55:7346-7351, 2012.

[13] C.J.L. Hermes, F.R. Loyola, and V.S. Nascimento Jr. A semi-empirical correlation for the frost density. International Journal of Refrigeration, 46:100-104, 2014. 